\title{
Genetic analysis of yield and fiber quality traits in upland cotton (Gossypium hirsutum L.) cultivated in different ecological regions of China
}

SHAHZAD Kashif ${ }^{\dagger}, \mathrm{LI}_{\mathrm{Xue}}^{\dagger}{ }^{\dagger}$, QI Tingxiang, GUO Liping, TANG Huini, ZHANG Xuexian, WANG Hailin, ZHANG Meng, ZHANG Bingbing, QIAO Xiuqin, XING Chaozhu* and WU Jianyong* (D)

\begin{abstract}
Background: Cotton is an important fiber crop worldwide. The yield potential of current genotypes of cotton can be exploited through hybridization. However, to develop superior hybrids with high yield and fiber quality traits, information of genetic control of traits is prerequisite. Therefore, genetic analysis plays pivotal role in plant breeding.

Results: In present study, North Carolina II mating design was used to cross 5 female parents with 6 male parents to produce 30 intraspecific $F_{1}$ cotton hybrids. All plant materials were tested in three different ecological regions of China during the year of 2016-2017. Additive-dominance-environment (ADE) genetic model was used to estimate the genetic effects and genotypic and phenotypic correlation of yield and fiber quality traits. Results showed that yield traits except lint percentage were mainly controlled by genetic and environment interaction effects, whereas lint percentage and fiber quality traits were determined by main genetic effects. Moreover, dominant and additiveenvironment interaction effects had more influence on yield traits, whereas additive and dominance-environment interaction effects were found to be predominant for fiber traits. Broad-sense and its interaction heritability were significant for all yield and most of fiber quality traits. Narrow-sense and its interaction heritability were non-significant for boll number and seed cotton yield. Correlation analysis indicated that seed cotton yield had significant positive correlation with other yield attributes and non-significant with fiber quality traits. All fiber quality traits had significant positive correlation with each other except micronaire.

Conclusions: Results of current study provide important information about genetic control of yield and fiber quality traits. Further, this study identified that parental lines, e.g., SJ48-1, ZB-1, 851-2, and DT-8 can be utilized to improve yield and fiber quality traits in cotton.
\end{abstract}

Keywords: Cotton, Hybrid, Genetic effects, Additive, Dominance, Correlation

\section{Background}

Cotton is the primary natural fiber crop used in textile industry, source of edible oil, and planted in more than 80 countries/regions of the world (Li et al. 2019). China is one of the major cotton producing and consuming countries in the world. The demand for fiber in the

\footnotetext{
*Correspondence: Chaozhuxing@126.com; dr.wujianyong@live.cn ${ }^{\dagger}$ Kashif SHAHZAD and Xue LI contributed equally to this work.

State Key Laboratory of Cotton Biology/Institute of Cotton Research, Chinese Academy of Agricultural Sciences/Key Laboratory for Cotton Genetic Improvement, Ministry of Agriculture and Rural Affairs, Anyang 455000, Henan, China
}

textile industry keeps increasing. To fulfill this challenge, yield potential of recent cotton genotypes can be increased through hybridization. In this regard, hybrids are developed through utilization of heterosis and cultivated in considerable area of China (Xing et al. 2007a). Main task of cotton breeders is to develop varieties or hybrids not only with superior yield and fiber quality but also with resistance against major pests, diseases and abiotic stresses such as adverse climatic conditions. The preliminary step to achieve such breeding aims is to select good genetic materials with suitable breeding methods.

(c) The Author(s). 2019 Open Access This article is distributed under the terms of the Creative Commons Attribution 4.0 International License (http://creativecommons.org/licenses/by/4.0/), which permits unrestricted use, distribution, and 
Parents genetically superior, physiologically effective and having good combining abilities are generally useful to explore heterosis in commercial hybrids. Estimation of combining ability or genetic effects is an important strategy to sort out superior and inferior parents coupled with better crosses (Basal and Turgut 2005; Khan et al. 2015; Rauf et al. 2005). Combining ability can be broken down into two components, i.e., general combining ability (GCA) and specific combining ability (SCA). Genetic effects are comprised of additive and non-additive genetic effects. GCA is associated with the parental lines and underlies additive gene contributions, whereas SCA is related to the comparative performance of hybrids and determines non-additive gene action, viz., dominant and epistatic.

Along with development of molecular genetics and breakthroughs in bioinformatics, genetic engineering, and genome sequencing, major changes have taken place in crop breeding research. Modern breeding methods are based on genes with an emphasis on improvement of individual characters. So, breeders must have strong knowledge about genetic control of traits to empower applications of molecular genetics to improve yield and quality of cotton crop ( $\mathrm{Li}$ et al. 2015; Wu et al. 2017a, 2017b; Yue et al. 2012; Zhang et al. 2018). To be in a concise perspective, genetic analysis has no substitute in crop breeding. Yield is a complex quantitative trait controlled by multiple genes frequently affected by environment. Estimation of genetic effects with quantitative genetic models is an important strategy to select future breeding materials. Four main genetic models are used in breeding to measure genetic effects, i.e., additive-dominance (AD) model (Ming et al. 2008), additivedominance-environment (ADE) model (Tang and Xiao 2014; Ye et al. 2008), additive-dominance-epistatic (ADAA) model (Song et al. 2014, 2015b), and additivedominance-maternal (ADM) model (Feng et al. 2011; Zhang et al. 2016). Genetic effects are influenced by materials, methods, and environments. Previous studies have shown that yield component traits are strongly influenced by dominant effects of genes, while additiveenvironment interaction effects also have certain contribution. In contrast, fiber quality traits are mainly controlled by additive effects of genes and are less affected by the environment (Cui et al. 2014; Jenkins et al. 2012; Song et al. 2015a; Zhang and Abdelraheem 2017; Zhang et al. 2017). Traits that are readily influenced by the environment can be effectively improved by adjusting cultivation measures, whereas traits whose phenotypic variation is mainly determined by genetic effects can be improved through genetics and breeding. High additive effects tend to facilitate early selection, and non-additive effects often suggest potential use of heterosis breeding.
Different mating designs are used in plant breeding to estimate the genetic variances of traits. However, choice of mating design is directly affected by objectives, time, space, and cost. Interestingly, North Carolina designs (NC) allow the breeders to measure additive, dominance and environment variances with less labor than diallel (Wen et al. 2015). In this study, NCII mating design was used to generate $30 \mathrm{~F}_{1}$ intraspecific upland cotton hybrids by using 5 female inbred parents and 6 male inbred parents. Field experiments were performed at three different locations for two consecutive years to obtain reliable phenotypic data for genetic analysis. The objective of this research was to obtain information on the genetic control of yield and fiber quality traits and correlation among traits under study. Our results will be important to select the base population for future hybrid breeding in upland cotton.

\section{Material and methods}

Plant materials, environment condition, and field design In 2015, we used 11 inbred lines to produce $30 F_{1}$ hybrids by using North Carolina mating design II (Li et al. 2019). The inbred lines Zhong 901-19 $\left(\mathrm{P}_{1}\right)$, L28-2 $\left(\mathrm{P}_{2}\right)$, SJ48-1 $\left(\mathrm{P}_{3}\right)$, ZB-1 $\left(\mathrm{P}_{4}\right)$, and $\mathrm{K} 8-1\left(\mathrm{P}_{5}\right)$ were used as female parents, while GC-8 $\left(\mathrm{P}_{6}\right), 851-2\left(\mathrm{P}_{7}\right), \mathrm{A} 2-10\left(\mathrm{P}_{8}\right)$, DT-8 $\left(\mathrm{P}_{9}\right), \mathrm{Z} 98-15\left(\mathrm{P}_{10}\right)$, and RP24-10 $\left(\mathrm{P}_{11}\right)$ were used as male parents. Among them, $\mathrm{P}_{4}, \mathrm{P}_{6}$, and $\mathrm{P}_{8}$ outperformed in the Yangtze River cotton belt, and $\mathrm{P}_{5}$ and $\mathrm{P}_{8}$ depicted better performance in the Northwest inland cotton belt, and all others were outstanding in the Yellow River cotton belt. Seeds of the resulting 30 hybrids and parental lines were planted in three different environmental regions of China. $\mathrm{E}_{1}$ was in Anyang, Henan $\left(114^{\circ} 35^{\prime} \mathrm{E}, 36^{\circ} 10^{\prime} \mathrm{N}\right.$; Yellow River cotton belt); $\mathrm{E}_{2}$ was in Alar, Xinjiang $\left(81^{\circ} 28^{\prime} \mathrm{E}, 40^{\circ} 55^{\prime} \mathrm{N}\right.$; Northwest inland cotton belt) and $\mathrm{E}_{3}$ was in Wuwei, Anhui $\left(117^{\circ} 75^{\prime} \mathrm{E}, 31^{\circ} 3^{\prime}\right.$ N; Yangtze River cotton belt). Planting and climate conditions at three locations are described in Additional file 1. All materials were planted in randomized complete block design with three replications in all above-mentioned environments during the period of 2016-2017. Seeds were sown in late April in consecutive years. Standard agronomic practices were followed throughout growing season.

\section{Evaluation of yield and fiber quality traits}

In mid-September, we counted total number of plants and total number of bolls for each line. Number of bolls (BN) per plant was calculated by dividing the total number of bolls by total number of plants. When more than $90 \%$ of bolls had opened, one fully opened boll was randomly selected from each of 50 individual plants, and weighed to estimate boll weight (BW). Seed cotton yield (SCY) was picked from each plot by hand and weighed 
after drying. Weight of seed cotton per plot was used to calculate seed cotton yield (SCY) per hectare. Lint percentage (LP) was calculated as follows: lint weight/seed cotton weight $\times 100$. Lint yield (LY) was calculated by multiplying the seed cotton yield by the lint percentage estimated from the 50 bolls. Subsamples of lint collected from each plot were sent to Cotton Fiber Quality Testing Center affiliated with the Chinese Ministry of Agriculture and Rural Affairs (Anyang, Henan) to evaluate fiber quality using a model High Volume Instrument (HVI_900) machine. Following data was collected: fiber length (FL, $\mathrm{mm}$; upper half mean length), fiber uniformity (FU, \%), fiber strength (FS, cN.tex $\left.{ }^{-1}\right)$, micronaire (MIC) and fiber elongation (FE, \%).

\section{Data analysis}

Genetic analysis was performed using QGAStation 2.0 software (http://ibi.zju.edu.cn/software/qga/index.htm) with ADE genetic model (Tang and Xiao 2014). The linear mixed model approach, i.e., minimum norm quadratic unbiased estimation (MIQNUE) was used to calculate variances and their contributions to the total variance. To estimate genetic effects, genotypic values based on population means were used with the adjusted unbiased prediction (AUP) method. The jackknife resampling method was used to calculate standard errors for each parameter by successive removal of individual blocks within each environment (Zhu 1992; Zhang et al. 2016). The $t$-test was used to assess significant differences.

\section{Results}

Genetic variance components of yield, yield components, and fiber quality traits

We estimated proportion of genetic variances for 30 hybrids and their parents based on three locations and 2 years data by using ADE genetic model for all traits under study. Results of all genetic variances can be seen in Fig. 1a. Result showed that additive variance $\left(\mathrm{V}_{\mathrm{A}}\right)$ was significant for LP, FL, FU, FS, MIC, and FE with $P<0.01$ (Additional file 2). Dominant variance $\left(V_{D}\right)$ of genetic was significant for all traits except FL and FE. However, it was larger for BN, BW, LP, SCY, and LY. The $\mathrm{V}_{\mathrm{D}}$ of $\mathrm{BW}, \mathrm{SCY}$ and $\mathrm{LY}$ were greater than the $\mathrm{V}_{\mathrm{A}}$, while the opposite was true for LP and all fiber quality traits. Results of genetic-environment interaction showed that the variance of additive-environment $\left(\mathrm{V}_{\mathrm{AE}}\right)$ interaction was larger than the variance of dominant-environment $\left(\mathrm{V}_{\mathrm{DE}}\right)$ interaction. $\mathrm{V}_{\mathrm{AE}}$ for $\mathrm{BW}, \mathrm{LP}$, and $\mathrm{SCY}$ were larger. However, it was smaller for $B N$. The $V_{A E}$ and $V_{D E}$ were equally important for LY. A significant $\mathrm{V}_{\mathrm{AE}}$ was noticed for MIC and FU. $\mathrm{V}_{\mathrm{DE}}$ was distinct for $\mathrm{FL}, \mathrm{FU}$, and FE. The ratio of genetic variance $\left(\mathrm{V}_{\mathrm{G}}\right)$ to phenotype variance $\left(\mathrm{V}_{\mathrm{P}}\right)$ for $\mathrm{BW}, \mathrm{LP}, \mathrm{LY}$, and FL was $>0.80$. This ratio for
$\mathrm{BN}, \mathrm{SCY}$, FS, and FE was $>0.70$ and for remaining traits was $>0.63$. These results indicated that these phenotypes were mainly inherited. Overall analysis results showed that BW, BN, SCY, and LY were mainly controlled by genetic and environment interaction effects (Fig. 1b). On the other hands, LP and fiber quality traits were mainly determined by the main genetic effects.

\section{Additive effects for yield, yield components, and fiber quality traits}

Additive effects (equivalent to GCA) are the average performance of a line in hybrid combinations due to additive gene action. It plays an important role to select superior inbred lines for specific trait or set of traits. Predicted additive effects of all parental lines based on all field tests for BN, LP, LY and fiber quality traits are listed in Table 1. The additive effects for BW and SCY were too small to analyze in this study. Result showed that female parent $\mathrm{P}_{4}$ had the highest significant additive effect for BN. It was determined that female parents showed significant positive additive effects for BN. In contrast, most of male parents showed significant negative additive effects for BN. Further results showed that $\mathrm{P}_{2}, \mathrm{P}_{3}$, and $\mathrm{P}_{4}$ had significant positive additive effects for LP. For LY trait, female parent $\mathrm{P}_{3}$ had the highest additive effect and male parents $\mathrm{P}_{7}$ had the lowest additive effect. The additive effects of $\mathrm{P}_{2}, \mathrm{P}_{3}$, and $\mathrm{P}_{8}$ were significantly positive for LY. All parental lines had significant additive effects for FL except $\mathrm{P}_{2}$. Female parent $\mathrm{P}_{3}$ showed the highest additive effect for FL. With regard to significant additive effects for $\mathrm{FU}, \mathrm{P}_{4}$ was the highest ranked genotypes among all parents. For FS, female parents $\mathrm{P}_{5}$ had the highest additive effect. However, $\mathrm{P}_{2}, \mathrm{P}_{6}, \mathrm{P}_{8}$, and $\mathrm{P}_{11}$ had a significant but negative additive effect for FS. All parental lines had significant additive effects for $\mathrm{MIC}$ except for those of $\mathrm{P}_{1}, \mathrm{P}_{2}, \mathrm{P}_{5}$, and $\mathrm{P}_{10}$. In context of additive effects for $\mathrm{FE}$, female parent $\mathrm{P}_{3}$ showed the highest and significant additive effects. Based on summarized results, it was concluded that parental lines $\mathrm{P}_{3}$ and $\mathrm{P}_{4}$ had the highest additive effects for yield and fiber quality traits. Whereby, $\mathrm{P}_{7}$ and $\mathrm{P}_{9}$ had the highest additive effects for majority of fiber quality traits.

\section{Dominant effects for yield, yield components, and fiber quality traits}

Dominant effects (equivalent to SCA) refer average performance of a cross due to non-additive gene actions. It provides an opportunity for utilization of heterosis in hybrid breeding. Predicted dominant effects for yield and yield component traits are listed in Table 2. Results showed that 17 out of the 30 hybrids had significant positive dominant effects for BW. The optimal cross to enhance $\mathrm{BW}$ was $\mathrm{P}_{3} \times \mathrm{P}_{9}$. Out of 30 crosses, 16 combinations 


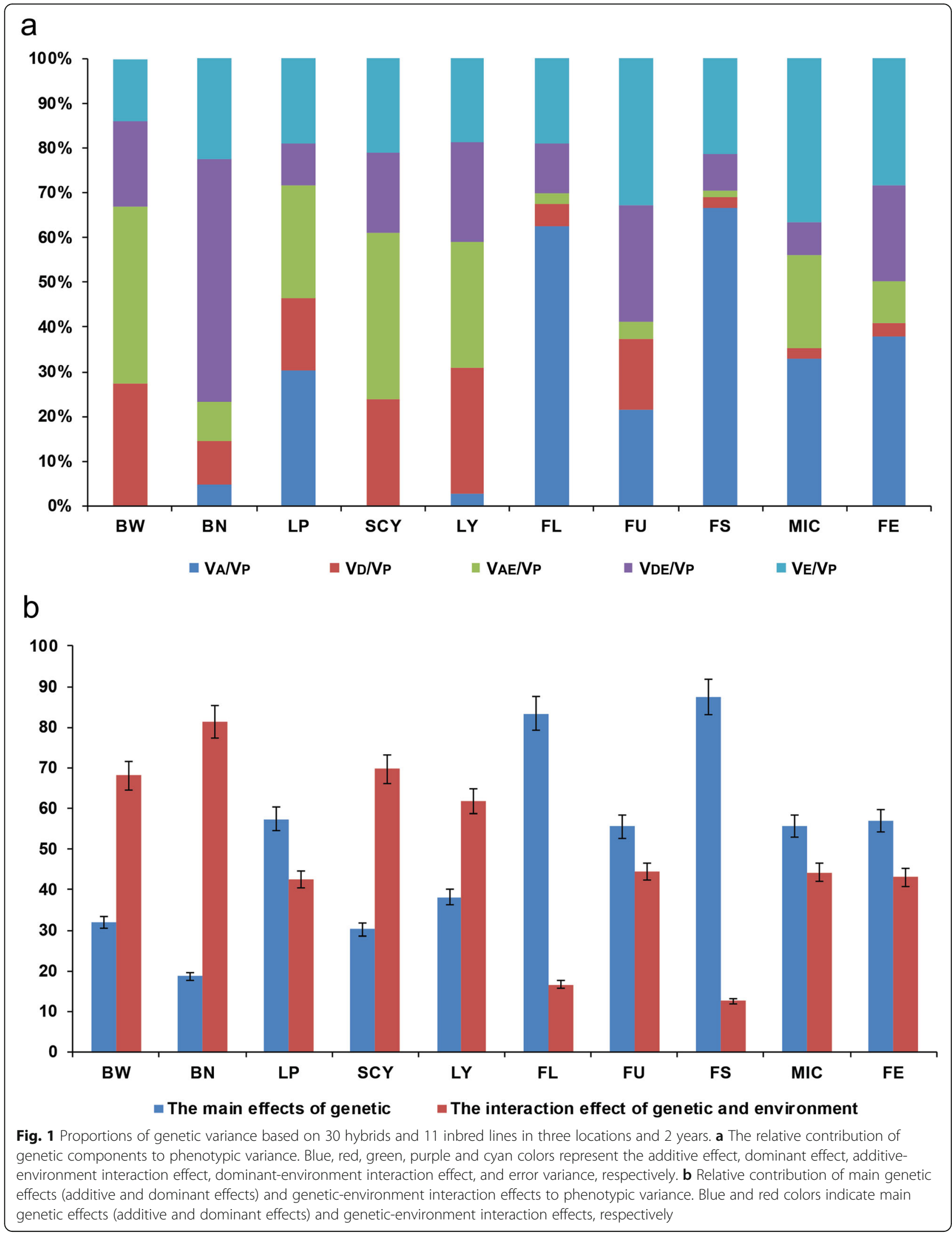


Table 1 Predicted additive effects for yield, yield components, and fiber quality traits

\begin{tabular}{lllllllll}
\hline & $B N$ & $L P$ & $L Y$ & $F L$ & $F U$ & $F S$ & $M I C$ & \\
\hline$P_{1}$ & $0.087^{b}$ & $-0.517^{a}$ & 1.200 & $-0.416^{c}$ & 0.059 & -0.209 & -0.003 & $-0.010^{a}$ \\
$P_{2}$ & $0.491^{a}$ & $1.034^{c}$ & $24.340^{b}$ & -0.049 & 0.030 & $-0.785^{c}$ & -0.027 & $0.014^{b}$ \\
$P_{3}$ & $0.087^{c}$ & $0.908^{c}$ & $24.445^{b}$ & $1.045^{c}$ & 0.082 & $0.890^{c}$ & $-0.178^{c}$ & $0.058^{c}$ \\
$P_{4}$ & $0.331^{c}$ & $0.609^{c}$ & 0.499 & $0.486^{c}$ & $0.482^{c}$ & $0.903^{c}$ & $0.070^{c}$ & $0.047^{c}$ \\
$P_{5}$ & 0.087 & $-0.437^{c}$ & -1.973 & $0.684^{c}$ & $0.390^{c}$ & $1.080^{c}$ & 0.005 & 0.006 \\
$P_{6}$ & $-0.431^{c}$ & $-0.330^{b}$ & 3.696 & $-0.972^{c}$ & $-0.140^{b}$ & $-1.000^{c}$ & $0.039^{c}$ & $-0.022^{a}$ \\
$P_{7}$ & 0.343 & $-1.673^{c}$ & $-35.659^{c}$ & $0.639^{c}$ & $-0.124^{b}$ & $0.814^{c}$ & $-0.182^{c}$ & $-0.018^{b}$ \\
$P_{8}$ & $-0.143^{\mathrm{a}}$ & $0.331^{b}$ & $16.153^{\mathrm{a}}$ & $-0.246^{c}$ & 0.003 & $-0.826^{c}$ & $0.187^{c}$ & $-0.023^{c}$ \\
$P_{9}$ & $-0.749^{\mathrm{b}}$ & -0.044 & $-35.288^{\mathrm{b}}$ & $0.425^{\mathrm{b}}$ & $0.308^{\mathrm{b}}$ & $0.495^{\mathrm{a}}$ & $-0.114^{c}$ & 0.012 \\
$P_{10}$ & -0.403 & 0.185 & 9.577 & $-0.688^{\mathrm{b}}$ & -0.428 & -0.115 & 0.037 & $-0.021^{\mathrm{b}}$ \\
$P_{11}$ & 0.299 & -0.064 & -6.986 & $-0.907^{c}$ & $-0.661^{c}$ & $-1.247^{c}$ & $0.167^{c}$ & $-0.042^{c}$ \\
\hline
\end{tabular}

${ }^{\mathrm{a}} \mathrm{b}$ and ${ }^{\mathrm{c}}$ denote significant differences at $0.1,0.05$ and 0.01 levels, respectively

had significant dominant effects in a desirable direction for BN. $P_{5} \times P_{11}$ was the best performing cross for this trait. Further, we found that 16 hybrids had significant dominant effects for LP and SCY. Top three crosses with higher dominant effects for LP were $\mathrm{P}_{1} \times \mathrm{P}_{11}, \mathrm{P}_{1} \times \mathrm{P}_{8}$, and $\mathrm{P}_{1} \times$ $\mathrm{P}_{10}$. On the other hand, top three crosses with higher dominant effects for SCY were $\mathrm{P}_{4} \times \mathrm{P}_{7}, \mathrm{P}_{4} \times \mathrm{P}_{9}$, and $\mathrm{P}_{5} \times \mathrm{P}_{6}$. It was observed that 17 crosses had a significant dominant effect for LY. $\mathrm{P}_{4} \times \mathrm{P}_{9}$ was the optimal cross to maximize LY followed by $\mathrm{P}_{4} \times \mathrm{P}_{7}$ and $\mathrm{P}_{3} \times \mathrm{P}_{6}$. Results of estimated dominant effects for fiber quality traits are given in Table 3. In results of fiber quality traits, most crosses had non-significant dominant effects. Only, 7 crosses had significant dominant effects for $\mathrm{FL}$ and cross $\mathrm{P}_{1} \times \mathrm{P}_{9}$ had significant dominant effect for this trait. Results showed that only 11 and 8 hybrids had significant dominant effects for FU and FS, respectively. Cross with higher dominant effects for FU was $\mathrm{P}_{4} \times \mathrm{P}_{6}$ and for FS, it was $\mathrm{P}_{1} \times \mathrm{P}_{9}$. For MIC, only13 crosses showed significant dominant effects. Cross $P_{1} \times P_{9}$ followed by $\mathrm{P}_{2} \times \mathrm{P}_{9}$ had higher dominant effects for this trait. According to results, only 7 out of total crosses had significant dominant effects for FE and cross $\mathrm{P}_{4} \times \mathrm{P}_{7}$ had highest significant dominant effect for this trait.

\section{Additive-environment interaction effects for yield, yield components, and fiber quality traits}

This study further analyzed the additive-environment interaction effects for yield and fiber quality traits for each environment. Analysis results can be seen in Table 4. Results showed that $\mathrm{P}_{6}$ for $\mathrm{BW}, \mathrm{P}_{2}$ for $\mathrm{BN}, \mathrm{SCY}$, MIC, and FE, $P_{5}$ for LP, and $P_{3}$ for LY had more positive and significant additive-environment interaction effects in $E_{1}$. Analysis result in environment $E_{2}$ showed that $P_{9}$ for $\mathrm{BW}$ and $\mathrm{MIC}, \mathrm{P}_{10}$ for $\mathrm{BN}, \mathrm{P}_{8}$ for $\mathrm{LP}, \mathrm{P}_{7}$ for SCY and $\mathrm{LY}$, and $\mathrm{P}_{3}$ for $\mathrm{FE}$ had more positive and significant effects. In environment $E_{3}$, it was observed that $P_{7}$ for $\mathrm{BW}, \mathrm{SCY}$ and $\mathrm{LY}, \mathrm{P}_{2}$ for $\mathrm{BN}, \mathrm{P}_{3}$ for $\mathrm{FL}, \mathrm{P}_{11}$ for $\mathrm{MIC}$, and
$\mathrm{P}_{4}$ for $\mathrm{FE}$ had more positive and significance additive into environment interaction effects. Collectively results represented that most of the additive-environment interaction effects for yield traits were significant but nonsignificant for fiber quality traits.

\section{Dominance-environment interaction effects for yield, yield components, and fiber quality traits}

Here, we calculated dominant-environment interaction effects for yield and yield-related traits (Additional file 3) and fiber quality traits (Additional file 4) in three locations based on 2 years of field experiments. A significant dominance-environment interaction effect was seen for yield parameters with most combinations, but these interaction effects varied among three locations. The effects of both crosses $\mathrm{P}_{2} \times \mathrm{P}_{11}$ and $\mathrm{P}_{5} \times \mathrm{P}_{9}$ for $\mathrm{BW}$ were significant in all locations. However, effect of $\mathrm{P}_{2} \times \mathrm{P}_{11}$ for $\mathrm{BW}$ was significant negative in $E_{1}$ and $E_{2}$, but significant positive in $E_{3}$. The effect of $\mathrm{P}_{5} \times \mathrm{P}_{9}$ was opposite to that of $\mathrm{P}_{2} \times \mathrm{P}_{11}$. The dominant-environment interaction effects of crosses $\mathrm{P}_{1} \times$ $\mathrm{P}_{7}, \mathrm{P}_{2} \times \mathrm{P}_{11}, \mathrm{P}_{3} \times \mathrm{P}_{7}, \mathrm{P}_{3} \times \mathrm{P}_{10}$ and $\mathrm{P}_{5} \times \mathrm{P}_{7}$ for $\mathrm{BN}$ were significant but either positive or negative. For example, $\mathrm{P}_{1} \times$ $P_{7}$ had positive effect in $E_{1}$ and $E_{2}$ and negative in $E_{3}$, whereas $\mathrm{P}_{2} \times \mathrm{P}_{11}, \mathrm{P}_{3} \times \mathrm{P}_{7}$, and $\mathrm{P}_{3} \times \mathrm{P}_{10}$ had shown negative effects in $E_{1}$ and $E_{2}$ but positive in $E_{3}$. The effect of $P_{5} \times P_{7}$ was positive in $E_{1}$ but negative in $E_{2}$ and $E_{3}$. For LP, it was observed that the effect of $\mathrm{P}_{1} \times \mathrm{P}_{9}$ was significantly positive in $E_{2}$ and $E_{3}$ but negative in $E_{1}$, whereas $P_{5} \times P_{7}$ showed significant negative effect in $E_{1}$ and $E_{3}$ but positive in $E_{2}$.

According to results, crosses $\mathrm{P}_{2} \times \mathrm{P}_{10}$ and $\mathrm{P}_{4} \times \mathrm{P}_{7}$ had significant dominance-environment interaction effects for SCY across three locations. Particularly, the effect of $\mathrm{P}_{2} \times$ $\mathrm{P}_{10}$ was positive in $\mathrm{E}_{1}$ but negative in $\mathrm{E}_{2}$ and $\mathrm{E}_{3} . \mathrm{P}_{4} \times \mathrm{P}_{7}$ showed positive additive-environment interactive effect in $E_{1}$ and $E_{3}$ but negative in $E_{2}$. Only combination that had a significant additive-environment interactive effect for LY was $\mathrm{P}_{2} \times \mathrm{P}_{10}$. It had positive in $\mathrm{E}_{1}$ but negative in $\mathrm{E}_{2}$ and 
Table 2 Predicted dominant effects for yield and yield component traits

\begin{tabular}{|c|c|c|c|c|c|}
\hline & BW & $\mathrm{BN}$ & $L P$ & SCY & LY \\
\hline$\overline{P_{1} \times P_{6}}$ & $0.318^{c}$ & 0.752 & 0.106 & $127.426^{c}$ & $50.005^{b}$ \\
\hline$P_{1} \times P_{7}$ & $0.264^{c}$ & -0.320 & $-0.915^{c}$ & 142.395 & 26.275 \\
\hline$P_{1} \times P_{8}$ & $0.101^{c}$ & 0.144 & $1.411^{c}$ & $92.933^{\mathrm{a}}$ & $82.264^{c}$ \\
\hline$P_{1} \times P_{9}$ & -0.034 & 0.241 & 0.589 & $151.437^{b}$ & $69.819^{b}$ \\
\hline$P_{1} \times P_{10}$ & $0.079^{b}$ & 0.068 & $1.167^{c}$ & 94.123 & $71.308^{b}$ \\
\hline$P_{1} \times P_{11}$ & -0.008 & 0.017 & $1.578^{c}$ & -1.003 & $46.430^{b}$ \\
\hline$P_{2} \times P_{6}$ & $0.090^{b}$ & $-0.198^{b}$ & 0.231 & $155.753^{b}$ & $70.734^{b}$ \\
\hline$P_{2} \times P_{7}$ & $0.096^{c}$ & $0.984^{b}$ & $0.367^{c}$ & $58.902^{b}$ & $29.639^{b}$ \\
\hline$P_{2} \times P_{8}$ & $0.110^{b}$ & 0.357 & 0.391 & $133.074^{b}$ & $68.041^{b}$ \\
\hline$P_{2} \times P_{9}$ & 0.144 & $1.039^{b}$ & 0.384 & 78.700 & 41.334 \\
\hline$P_{2} \times P_{10}$ & -0.040 & -0.463 & $1.017^{c}$ & 55.616 & 54.955 \\
\hline$P_{2} \times P_{11}$ & $0.100^{c}$ & 0.439 & -0.070 & 107.889 & 38.172 \\
\hline$P_{3} \times P_{6}$ & 0.074 & 0.592 & $0.881^{c}$ & $200.342^{b}$ & $108.113^{c}$ \\
\hline$P_{3} \times P_{7}$ & -0.049 & $1.141^{b}$ & -0.217 & 23.613 & -3.734 \\
\hline$P_{3} \times P_{8}$ & 0.071 & $0.549^{c}$ & $0.404^{a}$ & $132.214^{c}$ & $69.517^{c}$ \\
\hline$P_{3} \times P_{9}$ & $0.326^{b}$ & $-0.964^{b}$ & 0.715 & 48.601 & 49.444 \\
\hline$P_{3} \times P_{10}$ & 0.093 & $1.172^{b}$ & 0.511 & $210.484^{c}$ & $107.284^{c}$ \\
\hline$P_{3} \times P_{11}$ & $0.175^{b}$ & -0.458 & -0.023 & 28.722 & 10.129 \\
\hline$P_{4} \times P_{6}$ & 0.039 & -0.453 & -0.175 & 25.584 & 8.341 \\
\hline$P_{4} \times P_{7}$ & $0.128^{c}$ & $1.069^{c}$ & $0.817^{b}$ & $251.70^{c}$ & $118.717^{c}$ \\
\hline$P_{4} \times P_{8}$ & 0.052 & $0.514^{\mathrm{a}}$ & $-0.981^{c}$ & 70.602 & 5.758 \\
\hline$P_{4} \times P_{9}$ & $0.133^{b}$ & 0.227 & $0.805^{c}$ & $230.803^{c}$ & $119.441^{c}$ \\
\hline $\mathrm{P}_{4} \times \mathrm{P}_{10}$ & 0.136 & $-0.514^{b}$ & -0.142 & $100.090^{\mathrm{a}}$ & 35.207 \\
\hline $\mathrm{P}_{4} \times \mathrm{P}_{11}$ & $0.158^{c}$ & $0.796^{b}$ & $-0.492^{b}$ & $138.248^{b}$ & $38.249^{a}$ \\
\hline$P_{5} \times P_{6}$ & $0.076^{a}$ & $0.991^{b}$ & $0.519^{c}$ & $225.022^{c}$ & $106.719^{c}$ \\
\hline$P_{5} \times P_{7}$ & -0.085 & 0.248 & $-0.445^{a}$ & -26.861 & -27.692 \\
\hline$P_{5} \times P_{8}$ & $0.182^{a}$ & $0.809^{a}$ & 0.121 & $198.922^{\mathrm{a}}$ & $83.575^{a}$ \\
\hline$P_{5} \times P_{9}$ & 0.113 & $-0.363^{b}$ & -0.179 & -101.685 & -38.597 \\
\hline$P_{5} \times P_{10}$ & $0.103^{b}$ & $-0.721^{b}$ & $0.173^{b}$ & $126.428^{a}$ & $55.284^{b}$ \\
\hline$P_{5} \times P_{11}$ & $0.169^{c}$ & $1.453^{b}$ & $0.258^{c}$ & 2.153 & 2.521 \\
\hline
\end{tabular}

$E_{3}$. For fiber quality traits, it was noticed that $P_{1} \times P_{11}$ had a significant dominance-environment interaction effect for $\mathrm{FL}$ in the three locations, but effect was positive in $\mathrm{E}_{2}$ and negative in $E_{1}$ and $E_{3}$. For FU trait, the effect of $P_{5} \times$ $\mathrm{P}_{8}$ was significant in the three locations. The effect was significantly positive in $E_{1}$ and $E_{2}$ and negative in $E_{3}$. The effect of $\mathrm{P}_{5} \times \mathrm{P}_{11}$ for $\mathrm{FS}$ was significant negative in $\mathrm{E}_{1}$ and $E_{2}$ but positive in $E_{3}$. Analysis results for MIC trait showed that $\mathrm{P}_{2} \times \mathrm{P}_{9}$ showed significant positive interactive effect in $E_{2}$, while crosses $P_{2} \times P_{7}$ and $P_{5} \times P_{9}$ showed significant positive effects in $E_{3}$. Five crosses, i.e., $P_{1} \times P_{7}, P_{1} \times P_{9}$, $\mathrm{P}_{1} \times \mathrm{P}_{11}, \mathrm{P}_{3} \times \mathrm{P}_{9}$, and $\mathrm{P}_{5} \times \mathrm{P}_{6}$, showed significant effects for $\mathrm{FE}$ across all locations. From these, $\mathrm{P}_{1} \times \mathrm{P}_{7}, \mathrm{P}_{3} \times \mathrm{P}_{9}$, and $P_{5} \times P_{6}$ had negative effects in $E_{1}$ and $E_{3}$, but positive in
Table 3 Predicted dominant effects for fiber quality traits

\begin{tabular}{|c|c|c|c|c|c|}
\hline & $\mathrm{FL}$ & FU & FS & MIC & $\mathrm{FE}$ \\
\hline$\overline{P_{1} \times P_{6}}$ & -0.119 & 0.495 & -0.370 & $0.057^{b}$ & 0.024 \\
\hline$P_{1} \times P_{7}$ & 0.005 & -0.018 & 0.102 & -0.019 & -0.008 \\
\hline$P_{1} \times P_{8}$ & -0.110 & $0.306^{a}$ & -0.092 & $0.103^{a}$ & 0.007 \\
\hline$P_{1} \times P_{9}$ & $0.488^{c}$ & $0.445^{b}$ & $0.573^{b}$ & $-0.079^{a}$ & 0.011 \\
\hline$P_{1} \times P_{10}$ & -0.082 & $0.471^{a}$ & -0.013 & 0.029 & -0.009 \\
\hline$P_{1} \times P_{11}$ & $-0.165^{a}$ & -0.320 & $-0.134^{a}$ & 0.082 & $0.009^{b}$ \\
\hline$P_{2} \times P_{6}$ & 0.068 & -0.072 & -0.039 & $0.049^{c}$ & 0.013 \\
\hline$P_{2} \times P_{7}$ & $0.250^{b}$ & 0.168 & $-0.326^{a}$ & 0.005 & 0.014 \\
\hline$P_{2} \times P_{8}$ & 0.034 & $0.372^{b}$ & -0.027 & 0.027 & 0.000 \\
\hline$P_{2} \times P_{9}$ & 0.211 & 0.261 & 0.026 & $-0.054^{b}$ & 0.008 \\
\hline$P_{2} \times P_{10}$ & -0.055 & $0.473^{c}$ & $0.126^{b}$ & $0.039^{c}$ & 0.003 \\
\hline$P_{2} \times P_{11}$ & -0.040 & -0.153 & 0.014 & -0.017 & -0.002 \\
\hline$P_{3} \times P_{6}$ & -0.017 & 0.064 & $0.206^{b}$ & -0.016 & $0.009^{b}$ \\
\hline$P_{3} \times P_{7}$ & -0.010 & 0.068 & 0.020 & 0.023 & $-0.015^{a}$ \\
\hline$P_{3} \times P_{8}$ & 0.269 & 0.448 & $0.227^{b}$ & 0.022 & 0.015 \\
\hline$P_{3} \times P_{9}$ & 0.543 & 0.268 & 0.396 & -0.058 & 0.017 \\
\hline$P_{3} \times P_{10}$ & 0.246 & 0.096 & 0.021 & $-0.044^{a}$ & 0.003 \\
\hline$P_{3} \times P_{11}$ & 0.168 & $0.593^{a}$ & 0.136 & 0.012 & -0.001 \\
\hline$P_{4} \times P_{6}$ & 0.020 & $0.633^{b}$ & 0.003 & 0.051 & -0.005 \\
\hline$P_{4} \times P_{7}$ & 0.167 & 0.208 & 0.347 & -0.013 & $0.010^{b}$ \\
\hline$P_{4} \times P_{8}$ & $0.244^{a}$ & 0.208 & $0.300^{a}$ & -0.020 & $0.009^{a}$ \\
\hline$P_{4} \times P_{9}$ & 0.210 & $-0.406^{c}$ & -0.147 & $0.084^{b}$ & 0.009 \\
\hline$P_{4} \times P_{10}$ & $0.330^{\mathrm{b}}$ & 0.221 & 0.204 & $0.060^{\mathrm{b}}$ & 0.008 \\
\hline$P_{4} \times P_{11}$ & $0.197^{\mathrm{a}}$ & 0.164 & -0.104 & -0.007 & 0.004 \\
\hline$P_{5} \times P_{6}$ & -0.020 & -0.051 & 0.136 & $0.012^{a}$ & 0.001 \\
\hline$P_{5} \times P_{7}$ & -0.080 & $-0.485^{c}$ & -0.072 & $0.032^{b}$ & $0.007^{a}$ \\
\hline$P_{5} \times P_{8}$ & -0.226 & -0.184 & 0.074 & $-0.033^{b}$ & $-0.018^{a}$ \\
\hline$P_{5} \times P_{9}$ & 0.228 & $0.329^{b}$ & $0.292^{a}$ & $0.045^{c}$ & -0.002 \\
\hline$P_{5} \times P_{10}$ & $0.344^{a}$ & 0.207 & -0.074 & -0.007 & 0.008 \\
\hline$P_{5} \times P_{11}$ & 0.117 & $0.437^{a}$ & 0.096 & 0.021 & 0.010 \\
\hline
\end{tabular}

$E_{2}$. In contrast, $P_{1} \times P_{9}$ showed positive effect in $E_{1}$ and $E_{3}$, but negative in $E_{2}$. The effect of $P_{1} \times P_{11}$ was positive in $E_{2}$ and $E_{3}$ but negative in $E_{1}$.

\section{Analysis of heritability}

Heritability is a genetic parameter that measures the relative ratio of genetic variation to phenotypic variation. Here, broad-sense heritability $\left(\mathrm{h}_{\mathrm{B}}^{2}\right)$, narrow-sense heritability $\left(\mathrm{h}^{2}{ }_{\mathrm{N}}\right)$, broad-sense interaction heritability $\left(\mathrm{h}^{2}{ }_{\mathrm{BE}}\right)$, and narrow-sense interaction heritability $\left(\mathrm{h}^{2}{ }_{\mathrm{NE}}\right)$ were evaluated for all traits under study (Table 5). Results showed that heritability measures such as $h_{B}^{2}$ and $h_{B E}^{2}$ were highly significant and strong for all traits except for FS with non-

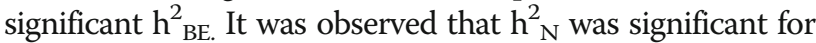
all traits except for $\mathrm{BW}$ and $\mathrm{SCY}$. According to results, $\mathrm{BW}$, 
Table 4 Predicted additive-environment interaction effects for yield, yield components, and fiber quality traits in three locations based on 2 years field test

\begin{tabular}{|c|c|c|c|c|c|c|c|c|c|c|}
\hline & BW & $\mathrm{BN}$ & $L P$ & SCY & LY & $\mathrm{FL}$ & $\mathrm{FU}$ & FS & MIC & $\mathrm{FE}$ \\
\hline \multicolumn{11}{|l|}{$\mathrm{E}_{1}$} \\
\hline$P_{1}$ & 0.001 & $1.083^{b}$ & $-0.753^{\mathrm{a}}$ & $261.067^{c}$ & $64.935^{b}$ & -0.067 & 0.188 & 0.054 & $0.162^{a}$ & $0.019^{c}$ \\
\hline$P_{2}$ & 0.03 & -0.111 & $0.64^{\mathrm{a}}$ & 6.02 & $31.275^{\mathrm{b}}$ & 0.126 & 0.116 & 0.014 & 0.047 & $0.031^{b}$ \\
\hline$P_{3}$ & 0.025 & 0.134 & 0.954 & $88.181^{c}$ & $76.008^{b}$ & 0.055 & -0.007 & -0.043 & -0.028 & -0.003 \\
\hline$P_{4}$ & -0.02 & $0.76^{a}$ & 0.729 & 34.393 & $35.15^{c}$ & 0.02 & $-0.109^{b}$ & 0.016 & 0.017 & $-0.019^{b}$ \\
\hline$P_{5}$ & -0.015 & -0.279 & $0.406^{b}$ & $-171.386^{b}$ & $-55.857^{\mathrm{a}}$ & 0.034 & 0.098 & 0.151 & -0.019 & 0.007 \\
\hline$P_{6}$ & $0.151^{b}$ & 0.061 & -0.24 & $190.076^{c}$ & $63.334^{b}$ & -0.166 & -0.061 & -0.025 & 0.017 & -0.013 \\
\hline$P_{7}$ & $-0.127^{a}$ & $-0.592^{b}$ & -1.447 & $-496.371^{b}$ & $-239.017^{c}$ & 0.022 & -0.12 & -0.067 & -0.051 & $-0.017^{\mathrm{a}}$ \\
\hline$P_{8}$ & $0.153^{\mathrm{a}}$ & -0.054 & -0.362 & 138.314 & 46.767 & 0.104 & 0.058 & 0.045 & -0.012 & $0.01^{b}$ \\
\hline$P_{9}$ & $-0.128^{\mathrm{a}}$ & -0.684 & 1.78 & $-331.879^{c}$ & $-76.805^{\mathrm{a}}$ & 0.114 & -0.024 & 0.041 & $-0.049^{b}$ & 0.015 \\
\hline$P_{10}$ & $0.113^{a}$ & -0.157 & $-0.528^{a}$ & $256.401^{b}$ & $86.728^{a}$ & -0.051 & -0.009 & 0.004 & -0.053 & -0.01 \\
\hline$P_{11}$ & $-0.183^{b}$ & -0.162 & -1.179 & 25.189 & -32.515 & -0.191 & -0.129 & $-0.19^{a}$ & -0.031 & -0.018 \\
\hline \multicolumn{11}{|l|}{$E_{2}$} \\
\hline$P_{1}$ & -0.057 & $0.321^{b}$ & 0.426 & -3.181 & 14.755 & -0.06 & -0.061 & -0.107 & 0.073 & $-0.015^{b}$ \\
\hline$P_{2}$ & $-0.074^{b}$ & $-0.368^{b}$ & $-0.354^{b}$ & $-42.001^{a}$ & $-32.737^{b}$ & $-0.099^{a}$ & -0.064 & -0.095 & -0.005 & -0.003 \\
\hline P3 & 0.013 & $-0.509^{b}$ & -0.357 & -28.529 & -27.881 & 0.217 & -0.115 & 0.235 & -0.118 & $0.035^{b}$ \\
\hline $\mathrm{P}_{4}$ & $0.24^{c}$ & -0.078 & -0.09 & $113^{b}$ & $37.14^{c}$ & 0.156 & 0.011 & 0.126 & $-0.045^{\mathrm{a}}$ & 0.024 \\
\hline$P_{5}$ & $-0.063^{\mathrm{a}}$ & -0.105 & $-0.298^{b}$ & -9.847 & -4.17 & 0.061 & -0.068 & 0.164 & 0.004 & 0.003 \\
\hline$P_{6}$ & -0.014 & -0.049 & -0.132 & $-114.551^{b}$ & $-45.52^{b}$ & -0.131 & 0.065 & -0.108 & $0.03^{b}$ & -0.001 \\
\hline$P_{7}$ & $-0.211^{c}$ & 0.197 & 0.267 & $157.965^{b}$ & $82.35^{c}$ & 0.118 & 0.024 & 0.201 & $-0.136^{b}$ & 0.001 \\
\hline$P_{8}$ & $-0.089^{b}$ & -0.209 & $0.936^{c}$ & -47.223 & -0.533 & -0.194 & -0.092 & -0.301 & $0.104^{c}$ & $-0.017^{c}$ \\
\hline$P_{9}$ & $0.507^{c}$ & $0.421^{b}$ & -1.222 & 95.676 & 7.783 & 0.319 & 0.406 & 0.182 & $0.159^{b}$ & 0.001 \\
\hline$P_{10}$ & $-0.076^{a}$ & $0.492^{b}$ & 0.332 & -24.098 & -4.969 & -0.132 & 0.019 & -0.132 & -0.042 & $-0.022^{a}$ \\
\hline$P_{11}$ & $-0.176^{b}$ & -0.113 & 0.492 & $-97.207^{a}$ & -26.216 & -0.255 & -0.125 & -0.165 & -0.024 & $-0.007^{\mathrm{a}}$ \\
\hline \multicolumn{11}{|l|}{$E_{3}$} \\
\hline$P_{1}$ & 0.027 & $-1.314^{b}$ & -0.2 & -204.661 & -76.855 & -0.055 & -0.094 & -0.021 & -0.237 & $-0.01^{\mathrm{a}}$ \\
\hline$P_{2}$ & $0.059^{b}$ & $0.985^{\mathrm{b}}$ & $0.768^{c}$ & $107.993^{c}$ & $58.969^{a}$ & -0.049 & -0.035 & -0.199 & $-0.067^{c}$ & $-0.019^{b}$ \\
\hline$P_{3}$ & 0.034 & $0.465^{\mathrm{a}}$ & $0.329^{a}$ & 16.094 & 9.628 & $0.186^{b}$ & 0.168 & 0.124 & -0.017 & 0.008 \\
\hline $\mathrm{P}_{4}$ & $-0.312^{c}$ & $-0.341^{b}$ & -0.018 & $-191.975^{\mathrm{a}}$ & $-71.112^{b}$ & 0.036 & 0.367 & 0.179 & 0.092 & $0.028^{b}$ \\
\hline$P_{5}$ & $0.163^{b}$ & 0.474 & $-0.554^{c}$ & 204.393 & 55.365 & $0.204^{a}$ & 0.188 & 0.07 & 0.02 & -0.005 \\
\hline$P_{6}$ & 0.021 & -0.455 & 0.035 & -29.585 & -9.083 & $-0.129^{a}$ & $-0.083^{a}$ & -0.223 & $-0.011^{a}$ & -0.002 \\
\hline $\mathrm{P}_{7}$ & $0.263^{c}$ & 0.749 & $-0.526^{b}$ & $242.421^{b}$ & $72.417^{c}$ & 0.14 & 0.027 & 0.156 & 0.02 & 0.003 \\
\hline$P_{8}$ & 0.028 & 0.116 & $-0.237^{a}$ & -8.838 & -8.072 & -0.018 & 0.036 & -0.038 & $0.08^{c}$ & $-0.009^{b}$ \\
\hline$P_{9}$ & $-0.323^{c}$ & -0.509 & -0.603 & 3.093 & -14.351 & -0.247 & -0.21 & -0.047 & $-0.214^{b}$ & -0.008 \\
\hline$P_{10}$ & -0.104 & -0.751 & $0.385^{a}$ & $-188.357^{c}$ & $-59.131^{a}$ & -0.119 & -0.249 & 0.087 & 0.128 & 0.017 \\
\hline$P_{11}$ & 0.146 & $0.583^{\mathrm{a}}$ & $0.622^{\mathrm{a}}$ & 49.426 & 42.225 & 0.049 & -0.115 & -0.089 & $0.208^{b}$ & -0.004 \\
\hline
\end{tabular}

${ }^{a, b}$ and ${ }^{c}$ denote significant differences at $0.1,0.05$ and 0.01 levels, respectively

SCY, and $\mathrm{LY}$ had significant and strong $\mathrm{h}_{\mathrm{B}}^{2}, \mathrm{~h}_{\mathrm{NE}}^{2}$, and $\mathrm{h}_{\mathrm{BE}}^{2}$. These findings put forth a clue that these traits can be improved through genetics, breeding and proper selection of experimental populations. All heritability estimates of LP, FU, FE, and MIC were significant and equally important. Further results revealed that $\mathrm{h}_{\mathrm{B}}^{2}$ and $\mathrm{h}^{2}{ }_{\mathrm{N}}$ of FL and FS were significant and strong as compared with $\mathrm{h}_{\mathrm{BE}}^{2}$ and $\mathrm{h}^{2}{ }_{\mathrm{NE}}$.
Genetic and phenotypic correlations between yield, yield components, and fiber quality traits

Coefficients of genetic and phenotypic correlation between yield and fiber quality parameters can be seen in Table 6. Results revealed that SCY and LY had significant positive correlation with LP, BW, and BN. Further, SCY and LY had positive correlation with FL, FU, MIC, 
Table 5 The heritability estimates of yield, yield components, and fiber quality traits based on three locations and 2 years field test

\begin{tabular}{lllll}
\hline & Heritability $\left(\mathrm{h}^{2}{ }_{\mathrm{N}}\right)$ & Heritability $\left(\mathrm{h}_{\mathrm{B}}{ }_{\mathrm{B}}\right)$ & Heritability $_{\left(\mathrm{h}^{2}{ }_{\mathrm{NE}}\right)}$ & Heritability $\left(\mathrm{h}^{2}{ }_{\mathrm{BE}}\right)$ \\
\hline BW & 0.000 & $0.275^{c}$ & $0.396^{c}$ & $0.587^{c}$ \\
BN & $0.048^{\mathrm{a}}$ & $0.145^{c}$ & $0.089^{\mathrm{a}}$ & $0.631^{c}$ \\
LP & $0.302^{c}$ & $0.465^{c}$ & $0.250^{c}$ & $0.345^{c}$ \\
SCY & 0.000 & $0.239^{c}$ & $0.371^{c}$ & $0.552^{c}$ \\
LY & $0.028^{\mathrm{a}}$ & $0.310^{c}$ & $0.281^{c}$ & $0.502^{c}$ \\
FL & $0.627^{c}$ & $0.674^{c}$ & $0.026^{\mathrm{a}}$ & $0.135^{c}$ \\
FU & $0.214^{c}$ & $0.373^{c}$ & 0.039 & $0.299^{\mathrm{a}}$ \\
FS & $0.666^{c}$ & $0.689^{c}$ & 0.016 & 0.100 \\
MIC & $0.330^{c}$ & $0.353^{c}$ & $0.207^{c}$ & $0.280^{\mathrm{b}}$ \\
FE & $0.380^{c}$ & $0.408^{c}$ & $0.094^{\mathrm{b}}$ & $0.308^{c}$ \\
\hline
\end{tabular}

Narrow-sense heritability $\left(h^{2}\right)$, Broad-sense heritability $\left(h^{2}\right)$, Narrow-sense interaction heritability $\left(h^{2}{ }_{N E}\right)$, Broad-sense interaction heritability $\left(h^{2}{ }_{B E}\right)$ ${ }^{\mathrm{a}},{ }^{\mathrm{b}}$ and ${ }^{\mathrm{c}}$ denote significant differences at $0.1,0.05$ and 0.01 levels, respectively

Table 6 Estimated genetic and phenotypic correlations between yield, yield components, and fiber quality traits

\begin{tabular}{|c|c|c|c|c|c|c|c|c|c|}
\hline Traits & LY & LP & BW & $\mathrm{BN}$ & $\mathrm{FL}$ & $\mathrm{FU}$ & FS & MIC & $\mathrm{FE}$ \\
\hline \multicolumn{10}{|l|}{ SCY } \\
\hline $\mathrm{R}_{\mathrm{p}}$ & $0.913^{c}$ & $0.211^{c}$ & $0.481^{c}$ & $0.453^{c}$ & 0.009 & $0.094^{a}$ & -0.055 & $0.187^{b}$ & $0.080^{\mathrm{a}}$ \\
\hline $\mathrm{R}_{\mathrm{G}}$ & $0.918^{c}$ & $0.246^{c}$ & $0.531^{c}$ & $0.606^{c}$ & 0.030 & 0.110 & -0.055 & 0.217 & $0.115^{a}$ \\
\hline \multicolumn{10}{|c|}{ LY } \\
\hline $\mathrm{R}_{\mathrm{p}}$ & & $0.524^{c}$ & $0.489^{c}$ & $0.425^{c}$ & 0.045 & $0.128^{a}$ & -0.062 & $0.238^{\mathrm{a}}$ & $0.180^{\mathrm{b}}$ \\
\hline $\mathrm{R}_{\mathrm{G}}$ & & $0.545^{c}$ & $0.516^{c}$ & $0.562^{c}$ & 0.049 & 0.149 & $-0.078^{a}$ & 0.248 & $0.224^{b}$ \\
\hline \multicolumn{10}{|c|}{$L P$} \\
\hline $\mathrm{R}_{\mathrm{p}}$ & & & 0.147 & $0.111^{b}$ & 0.050 & 0.107 & -0.095 & $0.242^{a}$ & $0.311^{b}$ \\
\hline $\mathrm{R}_{\mathrm{G}}$ & & & 0.119 & $0.153^{b}$ & 0.025 & 0.124 & $-0.145^{a}$ & 0.258 & $0.347^{a}$ \\
\hline \multicolumn{10}{|c|}{$\mathrm{FL}$} \\
\hline $\mathrm{R}_{\mathrm{P}}$ & & & & & & $0.540^{c}$ & $0.765^{c}$ & $-0.297^{\mathrm{c}}$ & $0.613^{c}$ \\
\hline $\mathrm{R}_{\mathrm{G}}$ & & & & & & $0.585^{c}$ & $0.849^{c}$ & $-0.424^{c}$ & $0.694^{c}$ \\
\hline \multicolumn{10}{|c|}{ FU } \\
\hline $\mathrm{R}_{\mathrm{p}}$ & & & & & & & $0.487^{c}$ & 0.064 & $0.479^{c}$ \\
\hline $\mathrm{R}_{\mathrm{G}}$ & & & & & & & $0.558^{c}$ & -0.071 & $0.626^{c}$ \\
\hline \multicolumn{10}{|c|}{ FS } \\
\hline $\mathrm{R}_{\mathrm{p}}$ & & & & & & & & $-0.357^{c}$ & $0.538^{c}$ \\
\hline $\mathrm{R}_{\mathrm{G}}$ & & & & & & & & $-0.493^{c}$ & $0.623^{c}$ \\
\hline \multicolumn{10}{|c|}{ MIC } \\
\hline $\mathrm{R}_{\mathrm{p}}$ & & & & & & & & & -0.082 \\
\hline $\mathrm{R}_{\mathrm{G}}$ & & & & & & & & & $-0.153^{b}$ \\
\hline
\end{tabular}


and FE. However, most of these correlations were nonsignificant, while correlation coefficients of SCY and LY with FS were negative and small. LP had significant positive correlation with $\mathrm{BN}$ and $\mathrm{FE}$. Between fiber quality traits, results of both genetic and phenotypic correlation analysis showed that FL had significant positive correlation with FU, FS, and FE but, significant negative correlation with MIC. FU had significant positive correlation with FS and FE and negative correlation with MIC but, latter relationship was non-significant. According to results, FS had significant positive correlation with FE and negative correlation with MIC. MIC and $\mathrm{FE}$ showed significant negative correlation with each other but, only their genetic correlation was significant. Notably, all these results suggest that yield can be improved along with yield component traits independent of fiber quality traits.

\section{Discussion}

Cotton varieties with superior yield, fiber quality, and environmental adaptation are very important for sustainable cotton production. In plant breeding research, three mating designs (factorial, nested and diallel) are generally used to perform genetic analysis. In previous studies of cotton, most researchers used diallel and line-tester designs to perform genetic analysis (Song et al. 2015b; Ye et al. 2008). In this study, the NCII design was used to improve the efficiency of yield and fiber quality traits. We analyzed comprehensive data of 2 years and three locations of yield and fiber quality traits to reveal genetic variance and their effects, heritability, and correlations.

\section{Genetic effects and their interaction with the environment}

Previously, it was observed in agronomic crops that yield traits are quantitatively controlled by micro-functional polygenes, vulnerable to the environment (Nyombayire et al. 2018; Reddy et al. 2016). Therefore, comprehensive genetic analysis in different environments is an important strategy for a successful breeding program. Our results revealed that yield and fiber quality traits were determined by different effects of genetics. In this regard, yield traits were mainly controlled by genetic and environment interaction effects, whereas LP and fiber quality traits were mostly determined by main genetic effects. These findings are similar to the previous study by Song et al. (2015b). These authors reported that LP and fiber quality traits showed significant additive and dominant effects, thus controlled by main genetic effects. Further results showed that dominant effects had stronger influence on yield parameters and additive effects had stronger influence on fiber quality traits. These results predict that yield and its contributing traits have complex genetics with more influence of environmental effects. Similar results have been reported by Ming et al. (2008), Li et al. (2016) and Song et al. (2015a, 2015b). However, some researchers also observed significant additive effects for yield traits related, but others reported contribution of additive and dominant effects for yield contributing traits (Liu and Zhu 2007; Xing et al. 2007b). To a particular interest, the inbred lines used in this study were developed by self-pollination over multiple generations belonging to three different cotton growing areas of China. Most of additive and dominant effects for yield and fiber traits were significant in this study. However, their interaction with environment was unstable across different locations. Results showed that parental lines $\mathrm{P}_{2}, \mathrm{P}_{3}$, and $\mathrm{P}_{4}$ had more additive effects for yield and fiber traits. However, $\mathrm{P}_{7}, \mathrm{P}_{9}$, and $\mathrm{P}_{10}$ were found to have high significant additive effects for most of fiber quality traits. According to results, significant positive dominant effects for yield traits were seen in more than $50 \%$ cross combinations, whereas most of crosses showed non-significant dominant effects for fiber quality traits. In context of dominance-environment interaction effects, $\mathrm{P}_{1} \times \mathrm{P}_{8}, \mathrm{P}_{1} \times \mathrm{P}_{10}$, and $\mathrm{P}_{2} \times \mathrm{P}_{10}$ in $\mathrm{E}_{1}$, $\mathrm{P}_{4} \times \mathrm{P}_{6}$ in $\mathrm{E}_{2}, \mathrm{P}_{3} \times \mathrm{P}_{7}$ and $\mathrm{P}_{5} \times \mathrm{P}_{11}$ in $\mathrm{E}_{3}$ showed significant positive for yield traits. For fiber quality traits, significant positive dominance-environment interaction effects were produced by $\mathrm{P}_{1} \times \mathrm{P}_{9}, \mathrm{P}_{4} \times \mathrm{P}_{10}, \mathrm{P}_{5} \times \mathrm{P}_{9}$, and $P_{5} \times P_{11}$ in $E_{3}$. Because dominance underlies the potential utility of heterosis, these crosses can be improved through further hybridization.

\section{Heritability of traits}

Heritability is a statistic that determines the degree of phenotypic variance due to genetic variance. Results of current studys showed that broad-sense and its interaction heritability were extremely significant for all yield traits. In previous studies, it was described that seed cotton yield, lint yield, boll weight, lint percentage, boll number showed the highest broad sense by environment interaction heritability (Song et al. 2015a; Zeng and Pettigrew 2015). However, some researchers reported that many yield traits such as lint yield, boll number per plant, boll weight, and lint percentage showed little additive variance and low heritability (Tang et al. 1996). Further results showed that narrow-sense heritability was significant for all studied traits except for BW and SCY. These heritability estimates showed that broad and narrow-sense heritability were ubiquitous, thus indicating that potential of yield improvement in upland cotton through genetics and breeding is still large. Moreover, environmental factors have considerable influence on gene expressions. So, breeders should select plant materials which are adapted to different environments. Results for fiber traits showed that fiber length and strength had strong broad and narrow-sense heritability, 
indicating that these traits can be improved through allopatric selection and shuttle breeding methods.

\section{Correlations between traits}

Relationships between traits play an important role in selection of plant material for future breeding. The results of this study showed that both phenotypic and genotypic correlations of SCY and LY were significantly positive with $\mathrm{LP}, \mathrm{BW}$, and $\mathrm{BN}$. Thus, these yield-related traits with genetic effects should be considered as main criteria of genotype selection to improve yield. Previous studies have shown that yield and its contributing traits showed significant positive correlation among each other (Song et al. 2015a; Tang et al. 1996; Meredith 1990). In our results, SCY and LY also showed positive correlation with FL, FU, MIC, and FE and negative with FS, but most of these correlation coefficients were small and statistically non-significant. Other than this, FL, FU, FS, and FE showed significant positive correlation with each other but MIC showed negative correlation with other fiber quality traits. In the study of Song et al. (2015b), significant positive correlations were observed among fiber traits. However, FE showed significant negative correlation with other fiber quality traits in their study. Results of correlation analysis anticipate that SCY and $\mathrm{LY}$ can be improved coupled with $\mathrm{BW}, \mathrm{BN}$, and LP independent of fiber quality traits. Finally, this study identified that parental lines, e.g., SJ48-1 (P3), ZB-1 (P4), 851-2 (P10), and DT-8 (P9), can be used to improve yield and fiber quality traits in cotton through hybridization.

\section{Conclusions}

In this study, results of genetic analysis showed that yield traits were controlled by genetic and environment interaction effects. In contrast, fiber quality traits were mainly controlled by the main genetic effects. A significant positive phenotypic and genetic correlation was observed between yield and its component traits. Fiber quality traits also showed significant positive correlation with each other. However, yield and fiber quality traits had non-significant correlation among each other. Altogether, our results provide valuable information about genetic control of yield and fiber quality traits. It will help to develop high yield cotton hybrids with improved fiber quality traits in future.

\section{Additional files}

Additional file 1: Climate statistics and planting arrangement in three locations of this study. (DOCX $15 \mathrm{~kb}$ )

Additional file 2: Proportions of variance components for yield, yield components, and fiber quality traits based on $30 F_{1}$ hybrids together with their 11 parental lines of upland cotton tested at three locations in China during 2016-2017. (DOCX $17 \mathrm{~kb}$ )

Additional file 3: Predicted dominance-environment interaction effects for yield and yield component traits in three locations based on 2 years filed test. (DOCX $32 \mathrm{~kb}$ )

Additional file 4: Predicted dominance-environment interaction effects for fiber quality traits in three locations based on 2 years filed test. (DOCX $32 \mathrm{~kb})$

\section{Abbreviations}

ADE: Additive-dominance-environment; BN: Boll number; BW: Boll weight; FE: Fiber elongation; FL: Fiber length; FS: Fiber strength; FU: Fiber uniformity; LP: Lint percentage; LY: Lint yield; MIC: Micronaire; NCII: North Carolina II; SCY: Seed cotton yield

\section{Acknowledgments}

The authors thank Liu YG (Institute of Cotton Research of CAAS) for intended recommendations made in the course of analysis. We thank Muhammad Yasir for his insightful comments on this paper, and thank the field staff for their assistance in field experiments. We also thank two reviewers for constructive suggestions that improved earlier draft of this paper.

\section{Authors' contributions}

Wu JY and Xing CZ conceived and designed the research. Qi TX, Gou LP, Tang HN, Zhang XX, and Wang HL constructed hybrid plant population. Zhang M, Zhang BB, and Qiao XQ helped field investigation. Li X performed data analysis. Shahzad K wrote the manuscript. Wu JY and Xing CZ contributed to the preparation of the final manuscript. All authors read and approved the final manuscript.

\section{Funding}

This research was supported by National Key Research and Development Program of China (2016YFD0101400).

\section{Availability of data and materials}

All data generated or analyzed in this study included in published article and additional files.

Ethics approval and consent to participate

Not applicable.

Consent for publication

Not applicable.

\section{Competing interests}

The authors declare that they have no competing interests.

Received: 16 May 2019 Accepted: 6 August 2019

Published online: 06 September 2019

\section{References}

Basal H, Turgut I. Genetic analysis of yield components and fiber strength in upland cotton (Gossypium hirsutum L.). Asian J Plant Sci. 2005;27(4):207-12.

Cui Y, Guo L, Xing C, et al. Genetic effects and heterosis of three-line hybrid cotton in different ecological environments. J Cotton Sci. 2014;26(1):1-9.

Feng $\mathrm{HJ}$, Sun $\mathrm{J}$, Wang J, et al. Genetic effects and heterosis of the fiber color and quality of brown cotton (Gossypium hirsutum L.). Plant Breed. 2011; 130(4):450-6. https://doi.org/10.1111/j.1439-0523.2010.01842.x.

Jenkins JN, McCarty JC, WU J, et al. Genetic effects of nine Gossypium barbadense $\mathrm{L}$. chromosome substitution lines in top crosses with five elite upland cotton G. hirsutum L. cultivars. Euphytica. 2012;187(2):161-73. https://doi.org/10.1 007/s10681-011-0580-1.

Khan SA, Khan NU, Gul R, et al. Combining ability studies for yield and fiber traits in upland cotton. J Anim Plant Sci. 2015;25(3):698-707.

Li B, Shi Y, Gong J, et al. Genetic effects and heterosis of yield and yield component traits based on Gossypium barbadense chromosome segment substitution lines in two Gossypium hirsutum backgrounds. PLoS One. 2016; 11(6):e0157978. https://doi.org/10.1371/journal.pone.0157978. 
Li F, Fan G, Lu C, et al. Genome sequence of cultivated upland cotton (Gossypium hirsutum TM-1) provides insights into genome evolution. Nat Biotechnol. 2015;33(5):524-30. https://doi.org/10.1038/nbt.3208.

Li X, Shahzad K, Guo L, et al. Using yield quantitative trait locus targeted SSR markers to study the relationship between genetic distance and yield heterosis in upland cotton (Gossypium hirsutum L.). Plant Breed. 2019;138(1): 105-13. https://doi.org/10.1111/pbr.12668.

Liu LW, Zhu SJ. Analysis of genetic effects and heterosis for yield and yield traits in transgenic insect resistant cotton (G. hirsutum L.). J Cotton Sci. 2007:19(1):33-7.

Meredith WR. Yield and fiber-quality potential for second-generation cotton hybrids. Crop Sci. 1990;30(5):1045-8.

Ming BL, Xiang MG, Yong SZ, et al. Genetic effect on yield and fiber quality traits of 16 chromosome substitution lines in upland cotton. Agric Sci China. 2008; 7(11):1290-7. https://doi.org/10.1016/S1671-2927(08)60177-7.

Nyombayire A, Derera J, Sibiya J, et al. Genotype x environment interaction and stability analysis for grian yield of diallel cross maize hybrids across tropical medium and highland ecologies. J Plant Sci. 2018;6(3):101-6. https://doi. org/10.11648/j.jps.20180603.14

Rauf SA, Khan TM, Nazir SH. Combining ability and heterosis in Gossypium hirsutum L. Int J Agric Biol. 2005;7(1):109-13.

Reddy KB, Reddy VC, Ahmed ML, et al. Combining ability study for yield and its component traits through diallel mating design in upland cotton (Gossypium hirsutum L.). J Cotton Res Dev. 2016;30(2):180-4.

Song M, Fan S, Pang C, et al. Genetic analysis of the antioxidant enzymes, methane dicarboxylic aldehyde (MDA) and chlorophyll content in leaves of the short season cotton (Gossypium hirsutum L.). Euphytica. 2014;198(1):15362. https://doi.org/10.1007/s10681-014-1100-x.

Song M, Fan S, Pang C, et al. Genetic analysis of yield and yield-related traits in short-season cotton (Gossypium hirsutum L.). Euphytica. 2015a;204(1):135-47. https://doi.org/10.1007/s10681-014-1348-1.

Song M, Fan S, Pang C, et al. Genetic analysis of fiber quality traits in shortseason cotton (Gossypium hirsutum L.). Euphytica. 2015b;202(1):97-108. https://doi.org/10.1007/s10681-014-1226-X.

Tang B, Jenkins JN, Watson CE, et al. Evaluation of genetic variances, heritabilities, and correlations for yield and fiber traits among cotton $F_{2}$ hybrid populations. Euphytica. 1996;91(3):315-22. https://doi.org/10.1016/j. fcr.2014.10.004

Tang F, Xiao W. Genetic association of within boll yield components and boll morphological traits with fiber properties in upland cotton (Gossypium hirsutum L.). Plant Breed. 2014;133(4):521-9. https://doi.org/10.1111/pbr.12176.

Wen J, Zhao X, Wu G, et al. Genetic dissection of heterosis using epistatic association mapping in a partial NCII mating design. Sci Rep. 2015;5:18376. https://doi.org/10.1038/srep18376.

Wu J, Zhang M, Zhang B, et al. Genome-wide comparative transcriptome analysis of CMS-D2 and its maintainer and restorer lines in upland cotton. BMC Genomics. 2017b;18(1):454. https://doi.org/10.1186/s12864-017-3841-0.

Wu J, Zhang M, Zhang $X$, et al. Development of InDel markers for the restorer gene $R f 1$ and assessment of their utility for marker-assisted selection in cotton. Euphytica. 2017a;213(11):251. https://doi.org/10.1007/ s10681-017-2043-9.

Xing CZ, Jing SR, Xing YH. Review and prospect on cotton heterosis utilization and study in China. J Cotton Sci. 2007a;19(5):337-45.

Xing CZ, Yu SX, Guo LP. Analysis for genetic effect and heterosis of insect resistant transgenic upland cotton crosses in different ecological environments. Sci Agric Sin. 2007b;40(5):1056-63.

Ye ZH, Mei YJ, Zou KQ, et al. Genetic dissection of net effects between yield and its components in sea island cotton (Gossypium barbadense L.). Agric Sci China. 2008;7(9):1052-60. https://doi.org/10.1016/S1671-2927(08)60146-7.

Yue Y, Zhang M, Zhang J, et al. Overexpression of the AtLOS5 gene increased abscisic acid level and drought tolerance in transgenic cotton. J Exp Bot. 2012;63(10):3741-8. https://doi.org/10.1093/jxb/ers069.

Zeng L, Pettigrew WT. Combining ability, heritability, and genotypic correlations for lint yield and fiber quality of upland cotton in delayed planting. Field Crop Res. 2015;171:176-83. https://doi.org/10.1016/j.fcr.2014.10.004.

Zhang B, Zhang X, Guo L, et al. Genome-wide analysis of Rf-PPR-like (RFL) genes and a new InDel marker development for Rf1 gene in cytoplasmic male sterile CMS-D2 upland cotton. J Cotton Res. 2018;1(1):12. https://doi.org/10.11 86/s42397-018-0013-y.

Zhang JF, Abdelraheem A. Combining ability, heterosis, and genetic distance among nine elite American Pima cotton genotypes (Gossypium barbadense L.). Euphytica. 2017;213(11):240. https://doi.org/10.1007/s106 81-017-2036-8

Zhang JF, Abdelraheem A, Wu JX. Heterosis, combining ability and genetic effect, and relationship with genetic distance based on a diallel of hybrids from five diverse Gossypium barbadense cotton genotypes. Euphytica. 2017;213(9):208. https://doi.org/10.1007/s10681-017-1997-y.

Zhang JF, Wu M, Yu J, et al. Breeding potential of introgression lines developed from interspecific crossing between upland cotton (Gossypium hirsutum L.) and Gossypium barbadense: heterosis, combining ability and genetic effects. PLoS One. 2016;11(1):e0143646. https://doi.org/10.1371/journal.pone.0143646.

Zhu J. Mixed model approaches for estimating genetic variances and covariances. J Biomath. 1992;7:1-11.
Ready to submit your research? Choose BMC and benefit from:

- fast, convenient online submission

- thorough peer review by experienced researchers in your field

- rapid publication on acceptance

- support for research data, including large and complex data types

- gold Open Access which fosters wider collaboration and increased citations

- maximum visibility for your research: over $100 \mathrm{M}$ website views per year

At BMC, research is always in progress.

Learn more biomedcentral.com/submissions 